\title{
The effect of functional endoscopic sinus surgery on patients with asthma and CRS with nasal polyps*
}

\author{
E. Proimos ${ }^{1}$, C.E. Papadakis ${ }^{1}$, T.S. Chimona ${ }^{1}$, D. Kiagiadaki ${ }^{1}$, E. Ferekidis ${ }^{2}$, \\ J. Yiotakis ${ }^{2}$ \\ ENT Department, Chania General Hospital, Chania, Crete, Greece \\ 2 ENT Department, Medical School, University of Athens, Hippokration Hospital, Athens, Greece
}

\begin{abstract}
SUMMARY Aim: To study the effect of functional endoscopic sinus surgery (FESS) in patients with chronic rhinosinusitis (CRS) and nasal polyps (NP) with concomitant asthma.

Design: The study was designed to evaluate prospectively whether FESS can influence parameters of asthma in patients with CRS with nasal polyps.

Methods and Results: One hundred thirty seven patients were recruited from the ENT-Allergy and Panedoscopy Clinic of the ENT Department. All selected patients underwent medical therapy for CRS and NP for 12 weeks, and in case of no improvement, they proceeded to surgical treatment. They also underwent pre- and post-treatment subjective and objective measurements for CRS and asthma. In the study, 86 patients were finally evaluated who completed the protocol and were followed up for a period of 12 months.

The patients showed statistically significant improvement of the objective measurements for asthma, from baseline to six and twelve months follow-up. No significant increase was found in the proportion of patients with well or very well overall asthma-control during the follow-up period. There was a clear improvement in the use of bronchodilators, oral steroids and need for hospitalization for asthma.

Conclusions: Obviously, there is a link between CRS with NP and asthma. The data analysis of our study supports the hypothesis that FESS could have beneficial effect on both diseases improving objective and subjective measurements.
\end{abstract}

Key words: endoscopic sinus surgery, chronic rhinosinusitis with nasal polyps, asthma

\section{INTRODUCTION}

Chronic rhinosinusitis (CRS) is one of the most common longterm illnesses in Europe and United States, affecting approximately up to $14 \%$ of the urban population ${ }^{(1,2)}$. CRS is a challenging condition to treat, due to the unclear pathophysiology, definition, and microbiology. An overview of current insight into the different aspects of rhinosinusitis are given by the European Position Paper on Rhinosinusitis and Nasal Polyps (EPOS) ${ }^{(3)}$, where there have been described evidence based diagnosis, medical and surgical treatment of CRS, and nasal polyps (NP). Conventional medical treatment of CRS with NP includes long term antibacterials, nasal and oral steroids, with adjunctive care involving antihistamines, mast cell stabilizers, antileukotrienes, antimycotics (topical application), capsaicin solution (topical application) and nasal douching ${ }^{(3)}$. Currently, functional endoscopic sinus surgery (FESS) is considered the standard treatment in clinically challenging CRS and in NP if medical treatment fails. This technique has the advantage of allowing good subjective and objective outcomes and is associated with minimum complications. Several studies with highly consistent results suggest that FESS in patients with CRS with $\mathrm{NP}$ is generally beneficial offering substantial symptomatic improvement ${ }^{(3,4)}$.

Asthma is a bronchial inflammation characterized by recurrent attacks of bronchial symptoms (breathlessness and wheezing) and bronchoconstriction in response to exposure to environmental factors ${ }^{(5)}$. Although the research in asthma has advanced rapidly in recent years, the etiology of asthma still remains unclear. A close relationship between CRS and asthma has been noticed for decades ${ }^{(6,7)}$. In clinical practice, we have noticed that many patients who suffer from asthma or allergic rhinitis report pre-existent CRS. The clinical data have demonstrated that surgical and non-surgical CRS management can improve clinical symptoms of CRS and asthma. These data suggest that substances derived from a sinus infection may 
play a role in the pathogenesis of asthma, with a still unknown but probably intrinsic mechanism ${ }^{(8,9)}$.

FESS in asthma patients with concomitant CRS with NP has predominately a positive effect with improvement of asthma severity, nasal breathing and quality of life in most patients ${ }^{(3,10-}$ 12)

Our study evaluates a group of 86 patients with CRS with NP and asthma, that underwent surgical treatment with FESS and followed up for a period of 12 months.

\section{MATERIALS AND METHODS}

\section{Study design}

Patient candidates for FESS were recruited from the ENTAllergy and Panendoscopy Clinic and from the Chest Physician Clinic in Chania General Hospital. The study protocol had been approved by Chania General Hospital and Athens Medical School Ethics Committees. The study ran from September of 2006 through March of 2009. Having applied the exclusion criteria (see below), the study was presented to 130 consecutive patients with a clinical diagnosis of CRS with NP and asthma. We did not define how many of them suffered from allergic rhinitis or aspirin sensitivity. One hundred eighteen patients amongst them accepted to participate, whereas 32 of them were

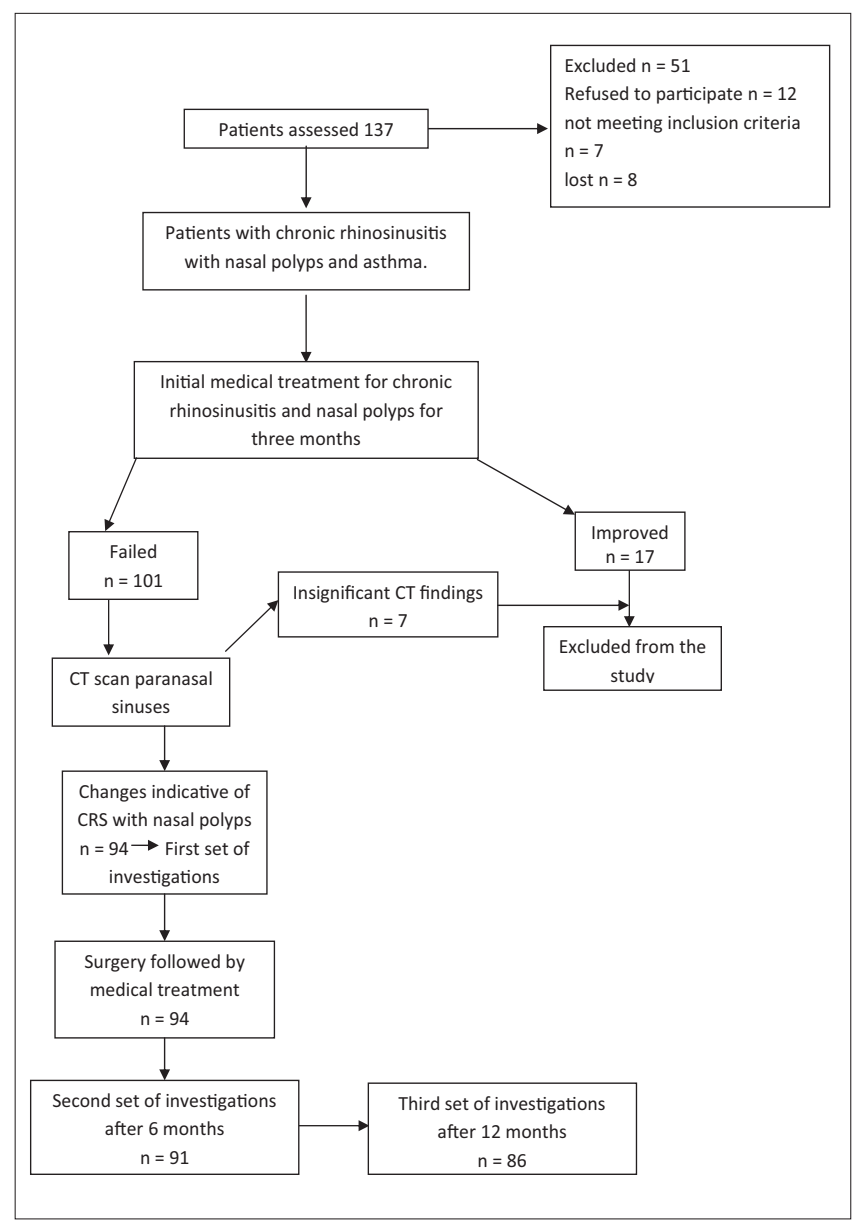

Figure 1. Study design. $\mathrm{CT}=$ Computed Tomography. finally excluded (17 with sufficient sinus symptoms control from the initial medical management with intranasal steroids and a five day course of prednisolone $0,5 \mathrm{mg} / \mathrm{Kg}$ in a single dose every morning, 7 patients with normal or insignificant findings in computed tomography (CT), and 8 patients who did not respect the follow-up). The design of the study is shown in Figure 1.

The diagnosis of CRS with NP is mainly based on the criteria described by EPOS/3 $2007^{(3)}$. CRS with or without NP is defined as: presence of two or more symptoms one of which should be either nasal blockage, obstruction, congestion, or nasal discharge (anterior/posterior nasal drip): \pm facial pain/pressure, \pm reduction or loss of smell, for more than 12 weeks, and with validation by telephone or interview. CRS is the major finding and nasal polyposis is considered a subgroup of this entity. For this study, the differentiation between CRS and NP must be based on out-patient endoscopy. The polyps should be bilateral, endoscopically visualized in the middle meatus. All patients underwent under local anesthesia full endoscopic examination with a $0^{\circ}, 4 \mathrm{~mm}$ rigid endoscope, using the three passes technique. Results were recorded and scored according to the Endoscopic Appearance Score system after Lund and Kennedy (13). C/T scanning was performed according to the Lund et al. protocol $^{(14)}$.

The exclusion criteria included: 1) females who were pregnant or lactating, 2) inability to follow the instructions within this protocol or known inability to attend all clinical visits within the intervals stated, 3) patients under 18 years of age, 4) systemic disease affecting the nose (cystic fibrosis, congenital or acquired gross immunodeficiency, congenital mucociliary problems e.g. primary ciliary dyskinesia), 5) non-invasive fungal balls, 6) systemic vasculitis and granulomatous diseases, 7) patients having any serious or unstable concurrent disease, 8) any structural nasal abnormalities e.g. severe nasal septum deviation, 9) medication affecting nasal mucosa, 10) rhinosurgery during the past 6 weeks, 11) use of systemic steroids 12 weeks before the study, 12) medications for acute infections of the unified airway within 2 weeks before the first visit. The study included 86 patients, 33 men and 53 women, with a mean age of 46.9 years \pm 14.9 .

\section{Subjective assessment}

Patients complained about nasal blockage or congestion, nasal discharge or postnasal drip, facial pain or pressure, reduction or loss of smell, headache and overall discomfort. The disease was evaluated using the nasal symptom scoring criteria according to the visual analogue scale (VAS) score ${ }^{(13)}$. The patients were asked to indicate on a $10 \mathrm{~cm}$ VAS the level of severity of their symptoms. For each set of investigations, we considered the score of each symptom and the total score.

Quality of Life Instruments, Sinonasal Outcome Test-20 (SNOT-20) This is a disease-specific (rhinosinusitis) health status instrument ${ }^{(15)}$. We actually use a modified version of SNOT 20 , the 
SNOT 22. We prefer the latter as this validated update has incorporated symptoms such as nasal blockage and alteration of sense of taste and smell, which have a considerable influence in the patient's quality of life ${ }^{(16)}$. The patients rate the severity of their condition on each of the 22 items using a $0-5$ category rating system. They are asked to identify the most important items for them, as well as the items (maximum 5) they hope to improve most with treatment. Sinonasal symptoms are evaluated in the list: sleep, fatigue, productivity, cognitive function, and emotional impact, cough, dizziness, facial pain and pressure, ear pain, nasal blockage and sense of taste and smell.

Asthma is evaluated according to the Asthma Control Test $\left(\mathrm{ACT}^{\mathrm{TM}}\right)$. This is a five-item self-administered survey, designed with a clinical working group to provide a broader assessment of asthma control at the individual patient level ${ }^{(17)}$. The five items examined are: a) shortness of breath; b) patient rating of control, c) use of rescue medication, d) asthma keeps you from getting as much done at work/school, e) asthma symptoms wake you up. The $\mathrm{ACT}^{\mathrm{TM}}$ is a validated instrument for the assessment and monitoring of asthma, fast for the patients to complete and easy for the clinicians to interpret and can be used either as a supplement to lung function testing, or as an independent measure of asthma control.

\section{Patient assessment}

All patients' assessment included a complete endoscopic evaluation under local anesthesia. Extent of pathology within the nasal cavity was scored according to the endoscopic appearance score after Lund and Kennedy ${ }^{(13)}$.

Those who failed to improve their symptoms after the initial medical treatment for CRS with NP, underwent CT scanning according to the Lund et al. protocol ${ }^{(14)}$ (direct coronal plane 5 mm slice thickness and $2.5 \mathrm{~mm}$ through the ostiomeatal complex). All patients with changes indicative of CRS with NP and a CT scan score, on the worst side, of at least 3 proceeded to FESS.

The objective measurements used for the upper and lower respiratory tracts were respectively nasal inspiratory peak flow (NIPF) and spirometry. NIPF measurements were performed with an In-Check ${ }^{\mathrm{TM}}$ inspiratory flow meter-HS (Clement Clarke International, Harlow, UK). The best of three attempts was recorded in each set of investigations. A flow less than 50 $1 /$ min was indicative of severe nasal obstruction, a flow between $50-801 / \mathrm{min}$ of moderate nasal obstruction, a flow between $80-1201 / \mathrm{min}$ of mild, and finally a flow over 120 $1 /$ min was considered as normal.

Spirometry was performed with a Spirobank-G-MIR S/N 006173 spirometer (MIR Medical International Research, Rome, Italy) three times and the highest measurement was used. The values considered were forced expiratory volume in one second $\left(\mathrm{FEV}_{1}\right)$, forced vital capacity $(\mathrm{FVC})$, the ratio of $\mathrm{FEV}_{1}$ : FVC and the peak expiratory flow (PEF). According to these test, patients were assessed for their asthma condition.

\section{Medical treatment}

In the beginning of the study, all patients received for the management of the sinus disease a 12 -week course of intranasal steroids (fluticasone propionate), applying $100 \mu \mathrm{g}$ ( 2 puffs) into each nostril twice daily. In addition, they were given a five-day course of prednisolone $0.5 \mathrm{mg} / \mathrm{kg}$ in a single dose every morning.

Pre-operatively, 32 patients were treated for asthma with oral steroids (prednisolone) in a dosage of $5 \mathrm{mg}$ to $20 \mathrm{mg} /$ day. The average dose of prednisolone pre-operatively was $10.6 \mathrm{mg} /$ day $(\mathrm{SD}=6.1)$ and the median dose was $10 \mathrm{mg} /$ day. During the period of medical polypectomy (five-day course of prednisolone $0.5 \mathrm{mg} / \mathrm{Kg}$ in a single dose every morning), no other oral steroids were given.

In addition, pre-operatively all asthmatic patients included in the study, were on bronchodilators, long acting $\beta 2$ adrenergic agonists (salmeterol $25 \mathrm{mcg} / \mathrm{puff}$ ) in a dose from 2 to 4 inhalations per day. During the study period, bronchial medication was kept stable for all patients.

Following FESS, all patients were prescribed a two-week course of clarithromycin $500 \mathrm{mg}$ twice daily. In addition, they received fluticasone propionate spray $100 \mu \mathrm{g}$ ( 2 puffs) in each nostril twice a day for twelve weeks, and they were given instructions for alkaline nasal douching twice daily 1 hour before application of fluticasone propionate spray.

\section{Surgical technique}

FESS was performed by the ENT consultants of our department under general anesthesia and consisted of removal of nasal polyps and diseased mucosa. The extent of the procedure was tailored to any single patient and depended on the extent of the sinus disease. The technique used was that described by Stammberger ${ }^{(18)}$ and Kennedy ${ }^{(19)}$. Microdebriders are available in our department and were used mainly in grade 2 and 3 polyposis. At the end of the operation sterile gauze dressing impregnated with ointment containing $2 \%$ sodium fusidate was applied in the middle meatus for 24 hours. The surgical procedure was recorded and scored according to Lund and Mackay scoring system ${ }^{(20)}$. Postoperatively, all patients were assessed with rigid endoscopy and scored with the same method used for the baseline assessment.

\section{Statistical analysis}

Variables were first tested for normality. Normal variables are expressed as mean \pm standard deviation; while variables with skewed distribution are expressed as median (interquartile range). Qualitative variables are expressed as absolute and relative frequencies. The paired Student's t-test was used to evaluate any possible differences in baseline and follow-up measurements for normally variables. Differences during the follow-up period for not normally distributed variables were estimated using Wilcoxon signed rank tests. Chi-square and Fisher's exact tests were used for the comparison of proportions. In case of multiple testing, statistical significance was set at 
Table 1. Changes in objective measurements for asthma during the follow-up period.

\begin{tabular}{|c|c|c|c|c|c|c|c|}
\hline & Baseline & 6 months & 12 months & $\begin{array}{l}\text { Baseline to } \\
6 \text { months }\end{array}$ & $\begin{array}{l}6 \text { to } 12 \\
\text { months }\end{array}$ & $\begin{array}{c}\text { Change } \\
\text { baseline to } \\
12 \text { months } \\
\end{array}$ & $\begin{array}{l}\text { Baseline to } \\
12 \text { months }\end{array}$ \\
\hline & Mean \pm SD & Mean \pm SD & Mean \pm SD & $\begin{array}{c}\text { p Paired } \\
\text { t-test }\end{array}$ & $\begin{array}{c}\mathrm{p} \text { Paired } \\
\text { t-test }\end{array}$ & Mean \pm SD & $\begin{array}{c}\text { p Paired } \\
\text { t-test }\end{array}$ \\
\hline FVC (\%) & $83.5 \pm 18.2$ & $84.1 \pm 18.0$ & $84.1 \pm 18.1$ & $<0.001$ & 0.007 & $0.6 \pm 1.6$ & $<0.001$ \\
\hline $\operatorname{FEV}_{1}(\%)$ & $66.0 \pm 16.4$ & $67.0 \pm 16.4$ & $66.7 \pm 16.4$ & $<0.001$ & 0.002 & $0.7 \pm 0.8$ & $<0.001$ \\
\hline PEF (\%) & $67.5 \pm 16.9$ & $68.5 \pm 17.1$ & $68.4 \pm 17.1$ & $<0.001$ & 0.013 & $0.9 \pm 0.4$ & $<0.001$ \\
\hline $\mathrm{FEV}_{1} / \mathrm{FVC}$ & $0.788 \pm 0.1$ & $0.794 \pm 0.09$ & $0.791 \pm 0.1$ & $<0.001$ & 0.007 & $0.003 \pm 0.01$ & 0.037 \\
\hline \multicolumn{8}{|l|}{ Overall asthma control } \\
\hline Well/Very well control, N (\%) & $72(83.7)$ & $76(88.4)$ & $75(87.2)$ & $0.373 \dagger$ & $0.810 \dagger$ & $3.5^{*}$ & $0.511 \dagger$ \\
\hline \multicolumn{8}{|l|}{ ACT } \\
\hline Not controlled, N (\%) & $7(8.1)$ & $0(0)$ & $2(2.3)$ & $0.014 \dagger$ & $0.167 \dagger$ & $-5.8^{*}$ & $0.086 \dagger$ \\
\hline $\begin{array}{l}\text { Adequately but not } \\
\text { completely controlled, N (\%) }\end{array}$ & $64(74.4)$ & $72(83.7)$ & $72(83.7)$ & $0.134 \dagger$ & $1.000 \dagger$ & $9.3^{*}$ & $0.134 \dagger$ \\
\hline Completely controlled, N (\%) & $15(17.4)$ & $14(16.3)$ & $12(14.0)$ & $0.839 \dagger$ & $0.674 \dagger$ & $-3.4^{*}$ & $0.540 \dagger$ \\
\hline
\end{tabular}

$* \%$ change; $\uparrow$ Fisher's exact test

$\mathrm{p}<0.001$ to control for type I error. P values reported are twotailed. Statistical significance was set at 0.05 and analysis was conducted using SPSS statistical software (version 13.0).

\section{RESULTS}

The sample consisted of 86 patients ( 33 men and 53 women) with mean age of $46.9 \pm 14.9$ years and a range from 20 to 70 years. Table 1 presents the changes in objective measurements for asthma during the follow-up period. FVC, $\mathrm{FEV}_{1}$ and $\mathrm{PEF}$ significantly increased both from baseline to six months and from six months to twelve months. Also, $\mathrm{FEV}_{1} / \mathrm{FVC}$ significantly increased both from baseline to six months and from baseline to twelve months. The mean increase from baseline to twelve months was $0.6 \pm 1.6$ for FVC $(\mathrm{p}<0.001), 0.7 \pm 0.8$ for $\mathrm{FEV}_{1}(\mathrm{p}<0.001)$ and $0.9 \pm 0.4$ for PEF $(\mathrm{p}<0.001)$. No significant increase was found in the proportion of patients with

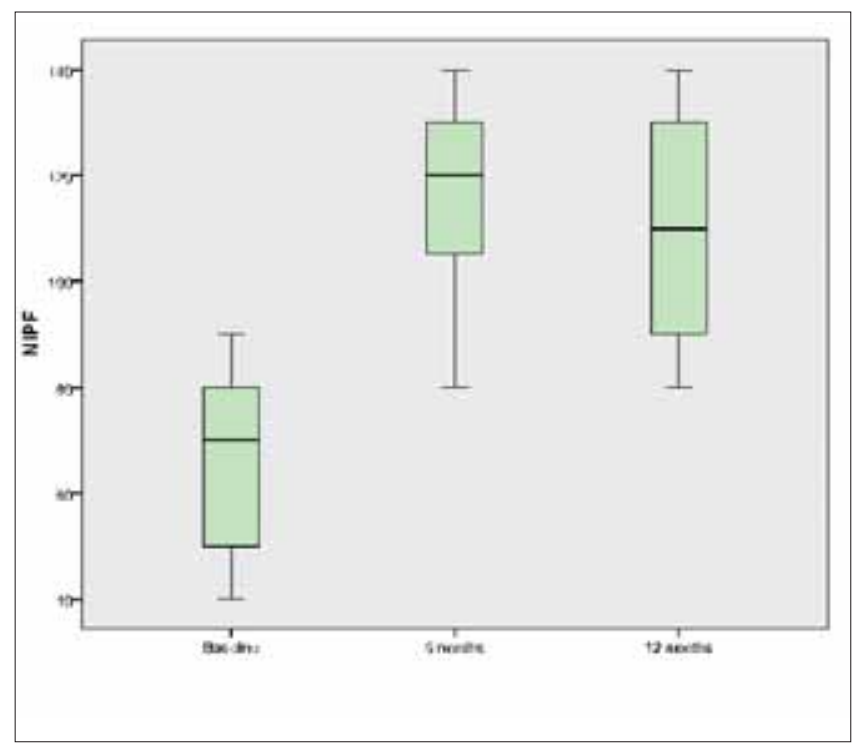

Figure 2. Median values of NIPF during the follow-up period. well or very well overall asthma control during the follow-up period.

The proportion of completely controlled patients according to Asthma Control Test was not significantly increased from baseline to six or twelve months. All VAS factors indicated a significant improvement both from baseline to six months and from six months to twelve months (Table 2). Also, measurements on NIPF were significantly increased, indicating improvement in symptoms from the nose. The median increase from baseline to twelve months $(\mathrm{p}<0.001)$ for NIPF was 42.5 (interquartile range: $35-50$ ) (Figure 2).

The results for improvement were similar concerning scores on SNOT 22 and SNOT 5 questionnaires. The mean decrease from baseline to twelve months was $-0.9 \pm 0.28$ for SNOT 22

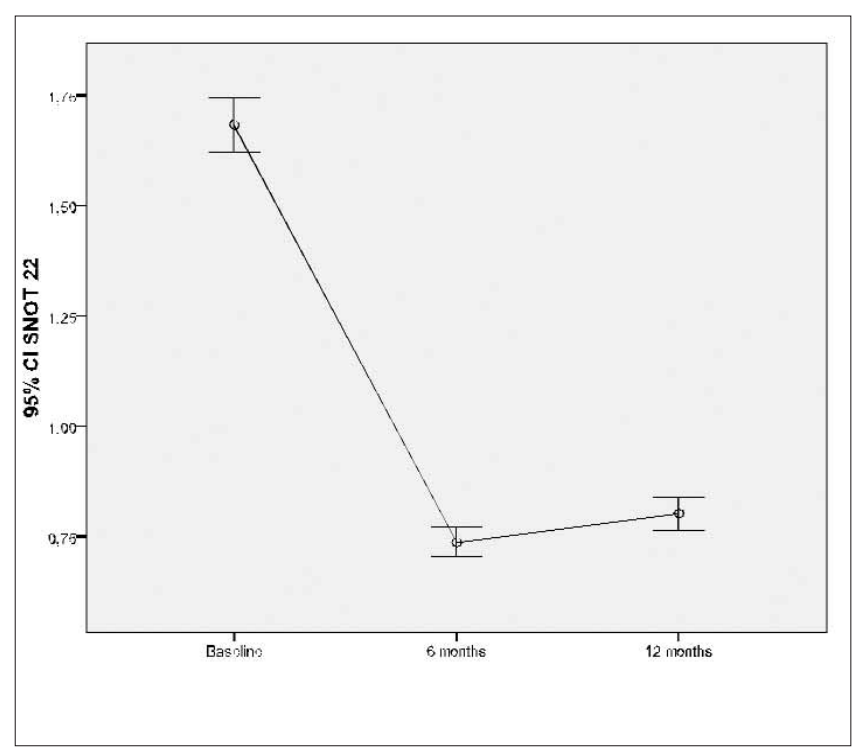

Figure 3. Mean values of SNOT 22 during the follow-up period. 
Table 2. Changes in quantitative measurements for nose during the follow-up period.

\begin{tabular}{|c|c|c|c|c|c|c|c|}
\hline & Baseline & 6 months & 12 months & $\begin{array}{l}\text { Baseline to } \\
6 \text { months }\end{array}$ & $\begin{array}{l}6 \text { to } 12 \\
\text { months }\end{array}$ & $\begin{array}{c}\text { Change } \\
\text { baseline to } \\
12 \text { months }\end{array}$ & $\begin{array}{l}\text { Baseline to } \\
12 \text { months }\end{array}$ \\
\hline & $\begin{array}{r}\text { Median } \\
\text { (range) }\end{array}$ & $\begin{array}{r}\text { Median } \\
\text { (range) }\end{array}$ & $\begin{array}{r}\text { Median } \\
\text { (range) }\end{array}$ & $\begin{array}{c}\mathrm{p} \\
\text { Wilcoxon test }\end{array}$ & $\begin{array}{c}\mathrm{p} \\
\text { Wilcoxon test }\end{array}$ & $\begin{array}{c}\text { Median } \\
\text { (range) }\end{array}$ & $\begin{array}{c}\mathrm{p} \\
\text { Wilcoxon test }\end{array}$ \\
\hline \multicolumn{8}{|l|}{ VAS } \\
\hline Blockage & $8(7,9)$ & $4(4,5)$ & $4(4,5)$ & $<0.001$ & 0.002 & $-4(-5,-3)$ & $<0.001$ \\
\hline Discharge & $7(5,8)$ & $3(2,3)$ & $3(3,3)$ & $<0.001$ & $<0.001$ & $-4(-4,-2)$ & $<0.001$ \\
\hline Smell & $3(2,4)$ & $3(2,3)$ & $3(2,3)$ & $<0.001$ & 0.018 & $0(-1,0)$ & 0.001 \\
\hline Facial pain & $5(2,6)$ & $2(2,3)$ & $3(2,3)$ & $<0.001$ & $<0.001$ & $-2(-3,0)$ & $<0.001$ \\
\hline Headache & $2(2,3)$ & $2(2,2)$ & $2(2,3)$ & $<0.001$ & $<0.001$ & $0(-1,1)$ & 0.492 \\
\hline Overall discomfort & $6(5,7)$ & $3(2,4)$ & $3(3,4)$ & $<0.001$ & 0.016 & $-3(-4,-2)$ & $<0.001$ \\
\hline NIPF & $70(50,80)$ & $120(105,130)$ & $110(90,130)$ & $<0.001$ & $<0.001$ & $42.5(35,50)$ & $<0.001$ \\
\hline SNOT 22, mean \pm SD & $1.7 \pm 0.3$ & $0.7 \pm 0.2$ & $0.8 \pm 0.2$ & $<0.001 \dagger$ & $<0.001 \dagger$ & $-0.9 \pm 0.28^{*}$ & $<0.001 \dagger$ \\
\hline SNOT 5 , mean \pm SD & $3.2 \pm 0.4$ & $1.4 \pm 0.3$ & $1.6 \pm 0.4$ & $<0.001 \dagger$ & $<0.001 \dagger$ & $-1.6 \pm 0.45^{*}$ & $<0.001 \dagger$ \\
\hline
\end{tabular}

$*$ mean $\pm \mathrm{SD} ; \uparrow$ Student's paired t-test

Table 3. Changes in qualitative measurements for nose during the follow-up period.

\begin{tabular}{|c|c|c|c|c|c|c|c|}
\hline & Baseline & 6 months & 12 months & $\begin{array}{c}\text { Baseline to } \\
6 \text { months }\end{array}$ & $\begin{array}{l}6 \text { to } 12 \\
\text { months }\end{array}$ & $\begin{array}{c}\text { Change } \\
\text { baseline to } \\
12 \text { months }\end{array}$ & $\begin{array}{l}\text { Baseline to } \\
12 \text { months }\end{array}$ \\
\hline & n (\%) & n (\%) & n ( $\%)$ & $\mathbf{p}^{*}$ & $\mathbf{p}^{*}$ & $\%$ & $\mathbf{p}^{*}$ \\
\hline \multicolumn{8}{|l|}{ Polyp (left) } \\
\hline Absent & $0(0.0)$ & $83(96.5)$ & 79 (91.9) & $<0.001$ & 0.192 & 91.9 & $<0.001$ \\
\hline $\begin{array}{l}\text { Polyps confined to the middle } \\
\text { meatus }\end{array}$ & $52(60.5)$ & $3(3.5)$ & $7(8.1)$ & $<0.001$ & 0.192 & -52.3 & $<0.001$ \\
\hline $\begin{array}{l}\text { Polyps beyond the middle } \\
\text { meatus but not completely } \\
\text { blocked / Polyps cause complet } \\
\text { obstruction }\end{array}$ & $34(39.5)$ & $0(0.0)$ & $0(0.0)$ & $<0.001$ & 1.000 & -39.5 & $<0.001$ \\
\hline \multicolumn{8}{|l|}{ Polyp (right) } \\
\hline Absent & $0(0)$ & $83(96.5)$ & $80(93.0)$ & $<0.001$ & $0.496 \dagger$ & 93.0 & $<0.001$ \\
\hline $\begin{array}{l}\text { Polyps confined to the middle } \\
\text { meatus }\end{array}$ & $37(43.0)$ & $3(3.5)$ & $6(7.0)$ & $<0.001$ & $0.496 \dagger$ & -36.0 & $<0.001$ \\
\hline $\begin{array}{l}\text { Polyps beyond the middle } \\
\text { meatus but not completely } \\
\text { blocked / Polyps cause complete } \\
\text { obstruction }\end{array}$ & $49(57.0)$ & $0(0.0)$ & $0(0.0)$ & $<0.001$ & 1.000 & -57.0 & $<0.001$ \\
\hline \multicolumn{8}{|l|}{ Oedema left } \\
\hline Mild to Severe & $86(100)$ & $9(10.5)$ & $46(53.5)$ & $<0.001$ & $<0.001$ & -46.5 & $<0.001$ \\
\hline \multicolumn{8}{|l|}{ Oedema right } \\
\hline Mild to Severe & $86(100)$ & 16 (18.6) & 53 (61.6) & $<0.001$ & $<0.001$ & -38.4 & $<0.001$ \\
\hline \multicolumn{8}{|l|}{ Discharge (left) } \\
\hline No discharge & $0(0.0)$ & $83(96.5)$ & 59 (68.6) & $<0.001$ & $<0.001$ & 68.6 & $<0.001$ \\
\hline Clear discharge & $66(76.7)$ & $3(3.5)$ & $27(31.4)$ & $<0.001$ & $<0.001$ & -45.3 & $<0.001$ \\
\hline Thick discolored & $20(23.3)$ & $0(0.0)$ & $0(0.0)$ & $<0.001$ & 1.000 & -23.3 & $<0.001$ \\
\hline \multicolumn{8}{|l|}{ Discharge (right) } \\
\hline No discharge & $0(0)$ & $83(96.5)$ & $33(38.4)$ & $<0.001$ & $<0.001$ & 38.4 & $<0.001$ \\
\hline Clear discharge & $62(72.1)$ & $3(3.5)$ & 53 (61.6) & $<0.001$ & $<0.001$ & -10.5 & 0.145 \\
\hline Thick discolored & $24(27.9)$ & $0(0.0)$ & $0(0.0)$ & $<0.001$ & 1.000 & -27.9 & $<0.001$ \\
\hline \multicolumn{8}{|l|}{ Scarring (left) } \\
\hline Mild to Severe & $0(0.0)$ & $4(4.7)$ & $4(4.7)$ & $0.121 \dagger$ & $1.000 \dagger$ & 4.7 & $0.121 \dagger$ \\
\hline \multicolumn{8}{|l|}{ Scarring (right) } \\
\hline Mild to Severe & $0(0.0)$ & $0(0.0)$ & $0(0.0)$ & & & & \\
\hline
\end{tabular}

* chi-square test; $†$ Fisher's exact test 
$(\mathrm{p}<0.001$; Figure 3 ) and $-1.6 \pm 0.45$ for SNOT $5(\mathrm{p}<0.001)$. As expected, the proportion of patients with NP was significantly decreased at six and twelve months (Table 3). Polyps on the left were absent in $91.9 \%$ of the patients at twelve months, while polyps on the right were absent in $93 \%$ of the patients in twelve months. Furthermore, the number of patients with edema on the left or the right was significantly decreased $(\mathrm{p}<0.001)$. All patients had clear or thick discolored discharge before surgery. The proportion of patients without discharge (Table 3) both on the left and the right was significantly increased after the surgery $(\mathrm{p}<0.001)$. None of the patients had thick discolored discharge both in six and twelve months follow-up.

The proportion of patients with hospitalizations significantly decreased from baseline to six months $(24.4 \%$ vs. $11.6 \%$, $\mathrm{p}=0.028)$ and from baseline to 12 months $(24.4 \%$ vs. $12.8 \%$, $\mathrm{p}=0.018$ ). Additionally, a similar trend was found in the use of oral steroids. The reduction in the use of steroids was significant from baseline to six months $(37.2 \%$ vs. $19.8 \%, \mathrm{p}=0.011)$ and from baseline to twelve months (37.2\% vs. $20.9 \%$, $\mathrm{p}=0.018$ ). Finally, a significant reduction was found in the use of bronchodilator inhalers $(\mathrm{p}<0.001)$. In twelve months follow-up, 39\% of the patients used less bronchodilator inhalers, $51.8 \%$ the same and 9.2\% more. The reduction in the use of bronchodilator inhalers was significant $(\mathrm{p}<0.001)$.

\section{DISCUSSION}

CRS with NP and bronchial asthma are conditions usually seen independently, but in a considerable percentage not very well defined they can affect patients simultaneously. Comorbidity of the upper and lower respiratory tract has been for a long time suggested, but so far, there has not been any study eager to explain and document this link. A possible explanation has been attributed to the pathophysiology (irritating character) of the diseases as proposed by Marney ${ }^{(21)}$, but the precise mechanisms involved in the development of these processes remain to be elucidated.

Functional endoscopic sinus surgery has prevailed as the most indicated surgical method for treating CRS with NP, refractory to medical treatment ${ }^{(22,23)}$. The benefits from the operation on the upper respiratory tract symptoms can be subjectively and objectively measured. The influence of this improvement on the lower respiratory tract diseases and, especially, on asthma is not clearly defined.

Dunlop et al. ${ }^{(24)}$ in a study of 50 asthmatic patients with a history of chronic rhinosinusitis with or without NP reported statistically significant improvement in the postoperative need for hospitalization $(\mathrm{p}=0.225)$, and the postoperative need for oral steroids $(\mathrm{p}=0.202)$, but not in the overall asthma control. Uri et al. ${ }^{(10)}$ reported that in a group of 34 asthmatic patients with massive polyposis, FESS did not improve the asthma state, but had a statistically significant effect in prednisolone intake $(p=0.046)$, and inhalations of bronchodilators $(\mathrm{p}=0.001)$. Batra et al. ${ }^{(11)}$ reported in a group of 17 patients with CRS, nasal polyposis and concomitant, oral steroidsdependent, that asthma statistically significant improved in pulmonary function test $\mathrm{FEV}_{1}(\mathrm{p}<0.014)$ and use of oral steroids $(\mathrm{p}=0.048)$. Ragab et al. ${ }^{(25)}$ reported in a group of 90 patients with CRS and asthma who underwent medical and surgical therapy, a significant reduction in the use of systemic steroids and the number of hospitalizations for asthma, as well as a decrease in the mean use of bronchodilator inhalers in both groups. Additionally, in the surgical group a significant improvement in the use of bronchodilators, systemic steroids, hospitalizations for asthma, overall asthma control and $\mathrm{FEV}_{1}$ was recorded. Finally, a trend of improvement in Asthma Symptom Score, PEF, $\mathrm{FEV}_{1}$, was recorded in both groups. Ehnhage et al. ${ }^{(12)}$ found that FESS had statistically significant effects on the subjective and objective parameters in 68 patients with asthma and nasal polyposis. FESS reduced nasal symptoms, improved olfaction and NIPF, reduced asthma symptoms and improved PEFR. Senior et al. ${ }^{(26)}$ concluded in their study that FESS in 30 patients with CRS and asthma had positive impact in $89.9 \%$, no change was reported in $11.1 \%$, while no patients reported worsening of the subjective measurements for asthma. Regarding objective measurements, $46 \%$ reported improvement in bronchodilator inhalers use and 65\% reported improvement in oral steroids use. Park et al. ${ }^{(27)}$ reported in their study in 79 patients with CRS and asthma, $80 \%$ improvement in the subjective measurements for asthma and significant improvement in the need for hospitalization and use for oral steroids for asthma. Finally, Goldstein et al. ${ }^{(28)}$ reported that in a group of 13 patients with bronchial asthma and CRS refractory to medical treatment, FESS did not lead to significant improvement in asthma symptoms $(p=0.72)$, asthma medication $(\mathrm{p}=0.82), \mathrm{FVC}(\mathrm{p}=0.54)$ and $\mathrm{FEV}_{1}(\mathrm{p}=0.92)$.

In our study, there were patients with persistent asthma, requiring oral steroids and inhaled bronchodilators with $\mathrm{ACT}^{\mathrm{TM}}$ scoring from 25 to 19 or less (any level of control) with concomitant CRS with NP. The symptom baseline subjective scoring (SNOT 22) could be of any degree. We did not define how many of them suffered from allergic rhinitis or aspirin sensitivity based on the prospective study of Bonfils and Malinvaud ${ }^{(29)}$ in sixty three patients with nasal polyposis and possible asthma, who underwent FESS, which demonstrated that specific treatment of allergy did not modify postoperatively the symptoms intensity and steroid consumption for the upper airway disease.

Our results, regarding the disease of the upper respiratory tract (CRS with NP), are in accordance with a long term prospective randomized study by Rowe-Jones et al. about the effectiveness of FESS on CRS with or without NP ${ }^{(30)}$. In addition, our study confirmed the discrepancy between subjective and objective scoring regarding nasal symptoms. There was a tendency for 
improvement of the overall asthma control, not statistically significant, with no difference between the proportions of patients with good or very good overall asthma control during the follow-up period. A very important decrease was recorded, from $8.1 \%$ to $0 \%$ in the proportion of non-controlled patients at six months $(\mathrm{p}=0.014)$ according to Asthma Control Test, which would be very beneficial for the quality of life of the asthmatic patients. Most of the patients reported significant improvement of their asthma symptoms, which is in accordance with the objective measurements $\left(\mathrm{FEV}_{1}, \mathrm{FVC}, \mathrm{PEF}, \mathrm{FEV}_{1} / \mathrm{FVC}\right)$ both at six and twelve months follow-up.

There was a considerable decrease in use of bronchodilators and systemic steroids, as well as in the number of hospitalizations for asthma. It is important to point out that there was statistically significant improvement of all VAS factors between baseline, second and third set of investigations. The results from SNOT 22 and SNOT 5 scoring were similar (improvement) with major decrease of SNOT 5 (-1.6 \pm 0.45 vs $-0.9 \pm$ 0.28), which means that FESS satisfied the expectations of the patients on the most important items to them, offering maximum symptoms control and considerable influence in their quality of life. Data confirmed that there was no correlation between the endoscopic appearance score and subjective and objective assessment of the asthmatic condition.

Finally, data from our study confirmed that there is a statistically significant improvement in all subjective and objective measurements of nasal functions. It has to be pointed out that none of the patients had anatomic variations such as nasal septal deviation, concha bullosa, or displaced uncinate process, that could be considered as risk factors for developing CRS ${ }^{(3)}$. We believe that relieve of nasal blockage is a concomitant but not the major cause of asthma improvement.

The influence of FESS in patients with asthma is attributed to several mechanisms that seem to explain the link between upper and lower airways. This surgical approach aims at the restoration of normal nasal function (filtration, humidification, heating of incoming air), thus protecting from irritation of the lower airways. It is also well known that upper and lower airways communicate with several mechanisms such as neural reflexes and systemic pathways. FESS positively influences the amount of inflammatory mediators that can induce symptoms in the unified airways, reduce beta adrenergic blockade related to chronic rhinosinusitis and reduce postnasal drip. On the other hand, certain authors reported that sinus surgery has a negative effect upon asthma. Lamblin et al. ${ }^{(31)}$ in their study concluded that sinus surgery had negative impact upon objective measurements (Spirometry) of bronchial function.

Asthma etiology still remains unclear. Our clinical study supports the hypothesis that FESS has a positive influence in the lower airways function of the asthmatic patients preventing from triggering asthma symptoms. Recorded improvement of the subjective and objective parameters measured, should not only be attributed to alleviation of upper airway symptoms and to concomitant improvement of a patient's quality of life, but to the positive influence of FESS on the intrinsic mechanisms, which probably control the link between upper and lower respiratory tract. Improvement of the subjective and objective parameters measured reinforce our estimation that reduction of nasal symptoms only, could not play the dominant role in the post FESS condition of the lower respiratory tract and that asthma could be considered and treated as an inflammatory disease.

In conclusion, the data analysis of our study supports the hypothesis that FESS could improve objective and subjective measurements in patients with asthma and CRS with NP. FESS significantly increased spirometry parameters measured both at six and twelve months and decreased the proportion of non-controlled patients according to the Asthma Control Test. In addition, statistically significant beneficial effect was recorded regarding the need of asthmatic patients for hospitalization, use of oral steroids and bronchodilator inhalers. Furthermore, all the subjective and objective measurements regarding nasal symptoms were significantly improved. Our data confirm that FESS positively influences CRS with NP and concomitant asthma and therefore should be considered when medical treatment fails.

\section{ACKNOWLEDGEMENTS}

We would like to thank the Chest Medicine Department of Chania General Hospital, for the collaboration and specially, Eleni Michelaki, Chest Physician, for her continuous support.

\section{REFERENCES}

1. Durr DG, Desrosiers MY, Dassa C. Impact of rhinosinusitis in health care delivery: the Quebec experience. J Otolaryngol. 2001; 30: 93-97.

2. Goetzel RZ, Hawkins K, Ozminkowski RJ, et al. The health and productivity cost burden of the "top 10" physical and mental health conditions affecting six large U.S. employers in 1999. J Occup Environ Med. 2003; 45: 5-14.

3. Fokkens W, Lund V, Mullol J. European position paper on rhinosinusitis and nasal polyps. Rhinol Suppl. 2007; 20: 1-136.

4. Dalziel K, Stein K, Round A, et al. Systematic review of endoscopic sinus surgery for nasal polyps. Health Technol. Assess. 2003; 7 : $1-159$.

5. Eapen SS, Busse WW. Asthma. Clin Allergy Immunol. 2002; 16: 325-353.

6. Okayama M, Iijima H, Shimura $\mathrm{S}$, et al. Methacholine bronchial hyperresponsiveness in chronic sinusitis. Respiration. 1998; 65: 450-457.

7. Dejima K, Hama T, Miyazaki M, et al. A clinical study of endoscopic sinus surgery for sinusitis in patients with bronchial asthma. Int Arch Allergy Immunol. 2005; 138: 97-104.

8. Carayol N, Crampette L, Mainprice B, et al. Inhibition of mediator and cytokine release from dispersed nasal polyp cells by mizolastine. Allergy. 2002; 57: 1067-1070.

9. Braunstahl GJ, Hellings PW. Nasobronchial interaction mechanisms in allergic airways disease. Curr Opin Otolaryngol Head Neck Surg. 2006; 14: 176-82. 
10. Uri N, Cohen-Kerem R, Barzilai G, et al. Functional endoscopic sinus surgery in the treatment of massive polyposis in asthmatic patients. J Laryngol Otol. 2002; 116: 185-189.

11. Batra PS, Kern RC, Tripathi A, et al. Outcome analysis of endoscopic sinus surgery in patients with nasal polyps and asthma. Laryngoscope. 2003; 113: 1703-1706.

12. Ehnhage A, Olsson P, Kölbeck KG, et al., NAFS Study Group. Functional endoscopic sinus surgery improved asthma symptoms as well as PEFR and olfaction in patients with nasal polyposis. Allergy. 2009; 64: 762-769.

13. Lund VJ, Kennedy DW. Quantification for staging sinusitis. The Staging and Therapy Group. Ann Otol Rhinol Laryngol Suppl. 1995; 167: 17-21.

14. Lund VJ, Savy L, Lloyd G. Imaging for endoscopic sinus surgery in adults. J Laryngol Otol. 2000; 114: 395-397.

15. Leopold D, Ferguson BJ, Piccirillo JF. Outcomes assessment. Otolaryngol Head Neck Surg. 1997; 117: 58-68.

16. Browne JP, Hopkins C, Slack R, et al. Health-related quality of life after polypectomy with and without additional surgery. Laryngoscope. 2006; 116: 297-302.

17. Nathan RA, Sorkness CA, Kosinski M, Schatz M, Li JT, Marcus P, Murray JJ, Pendergraft TB. Development of the Asthma Control Test: A survey for assessing asthma control. Journal of Allergy and Clinical Immunology. 2004; 113: 59-65.

18. Stammberger H. Surgical technique. In Stammberger H, ed Functional Endoscopic Sinus surgery. The Messeklinger Technique. Philadelphia: BC Decker, 1991; 283-320.

19. Kennedy DW, Zinreich SJ, Shaalan H, Kuhn F, Naclerio R, Loch E. Endoscopic middle meatal antrostomy: theory, technique, and patency. Laryngoscope. 1987; 97: 1-9.

20. Lund VJ, Mackay IS. Staging in rhinosinusitus. Rhinology. 1993; 31: 183-184.

21. Marney SR Jr. Pathophysiology of reactive airway disease and sinusitis. Ann Otol Rhinol Laryngol. 1996; 105: 98-100.

22. Lund VJ. Evidence-based surgery in chronic rhinosinusitis. Acta Otolaryngol. 2001; 121: 5-9.

23. Smith TL, Mendolia-Loffredo S, Loehrl TA, et al. Predictive factors and outcomes in endoscopic sinus surgery for chronic rhinosinusitis. Laryngoscope. 2005; 115: 2199-2205.
24. Dunlop G, Scadding GK, Lund VJ. The effect of endoscopic sinus surgery on asthma: management of patients with chronic rhinosinusitis, nasal polyposis, and asthma. Am J Rhinol. 1999; 13: 261265.

25. Ragab S, Scadding GK, Lund VJ, et al. The treatment of chronic rhinosinusitis and its effect on asthma. Eur Resp J. 2006; 28: 6874.

26. Senior B. A, Kennedy D. W, Tanabodee J, et al. C. Long-term impact of functional endoscopic sinus surgery on asthma. Otolaryngol Head Neck Surg. 1999; 121: 66-68.

27. Park A. H, Lau J, Stankiewicz J, et al. The role of functional endoscopic sinus surgery in asthmatic patients. J Otolaryngol. 1998; 27: 275-280.

28. Goldstein MF, Grundfast SK, Dunsky EH, et al. Effect of functional endoscopic sinus surgery on bronchial asthma outcomes. Arch Otolaryngol Head Neck Surg. 1999; 125: 314-319.

29. Bonfils P, Malinvaud D. Influence of allergy in patients with nasal polyposis after endoscopic sinus surgery. Acta Oto-Laryngologica. 2008; 128: 186-192.

30. Rowe-Jones JM, Medcalf M, Durham SR, et al. Functional endoscopic sinus surgery: 5 year follow-up and results of a prospective, randomised, stratified, double-blind, placebo controlled study of postoperative fluticasone propionate aqueous nasal spray. Rhinology. 2005; 43: 2-10.

31. Lamblin C, Brichet A, Perez T, et al. Long-term follow-up of pulmonary function in patients with nasal polyposis. Am J Respiratory Crit Care Med. 2000; 161: 406-413.

\author{
Efklidis Proimos \\ ENT Dept. Chania General Hospital \\ Georgiladon 2573133 \\ Chania, Crete \\ Greece
}

Tel: +30-694-455 7577

E-mail: efklidispr@hotmail.com 